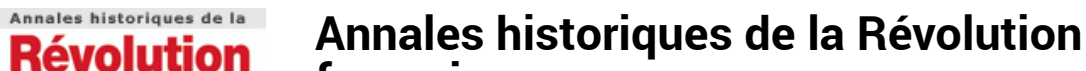

française française

360 | avril-juin 2010

Varia

\section{Monique Cottret, Tuer le tyran? Le tyrannicide dans}

l'Europe moderne

Paris, Fayard, 2009, 456 p., ISBN 978-2-213-64439-4, $25 €$

Michel Biard

\section{(2) OpenEdition}

Journals

Édition électronique

URL : https://journals.openedition.org/ahrf/11820

DOI : 10.4000/ahrf.11820

ISSN : 1952-403X

Éditeur :

Armand Colin, Société des études robespierristes

Édition imprimée

Date de publication : 1 juin 2010

Pagination : 250-252

ISBN : 978-2-200-92632-8

ISSN : 0003-4436

Référence électronique

Michel Biard, « Monique Cottret, Tuer le tyran? Le tyrannicide dans l'Europe moderne », Annales historiques de la Révolution française [En ligne], 360 | avril-juin 2010, mis en ligne le 01 juin 2013, consulté le 23 avril 2022. URL : http://journals.openedition.org/ahrf/11820 ; DOI : https://doi.org/10.4000/ahrf. 11820

Ce document a été généré automatiquement le 23 avril 2022

Tous droits réservés 


\title{
Monique Cottret, Tuer le tyran? Le tyrannicide dans l'Europe moderne
}

\author{
Paris, Fayard, 2009, 456 p., ISBN 978-2-213-64439-4, $25 €$
}

Michel Biard

\section{RÉFÉRENCE}

Monique Cottret, Tuer le tyran? Le tyrannicide dans l'Europe moderne, Paris, Fayard, 2009, 456 p., ISBN 978-2-213-64439-4, $25 €$

1 Affirmant avoir toujours été fascinée par le " on ne peut point régner innocemment » de Saint-Just, Monique Cottret entend ici proposer «l'histoire politique d'une idée, celle du tyrannicide », et non une histoire des idées politiques. "Ceux qui se réclament de Judith, ceux qui évoquent Brutus ne sont pas tout à fait les mêmes. Il y a ceux qui utilisent le poignard, ceux qui font des procès, les régicides individuels et les régicides collectifs. Beaucoup agissent au nom de Dieu, d'autres au nom de l'État ou du droit naturel, comme de l'impulsion divine ou de la raison ». Le tout suscite des questions récurrentes, car tous ces actes cherchent une légitimité : qui définit le tyran? qui peut autoriser la désobéissance, voire le meurtre? Pour cela, Monique Cottret cherche tout d'abord à définir un «outillage mental du tyrannicide moderne", rappelant notamment les ambiguïtés du christianisme primitif où chacun doit certes obéir au commandement « Tu ne tueras point ", mais où il est licite de tuer un tyran à l'exemple de Judith qui a inspiré toute une iconographie (dont la merveilleuse toile de Caravage qui orne la couverture de cet ouvrage. Sur cette iconographie, je me permets ici de renvoyer au catalogue d'une exposition organisée à Düsseldorf et Darmstadt en 1995-1996, Die Galerie der Starken Frauen, hélas passée un peu inaperçue, qui permet de comparer diverses représentations de Judith, dont les superbes toiles d'Artemisia Gentileschi et de Cristofano Allori). Cet « outillage mental » hérité de l'Antiquité repose aussi sur les hésitations des philosophes païens, les uns louant Brutus (Cicéron), d'autres rejetant son geste assassin (Sénèque). Ce «non, mais » et le tyrannicide dont 
Judith et Brutus sont désormais « deux anges tutélaires » se retrouvent au Moyen Âge, et Monique Cottret mentionne de nombreux textes à l'appui de sa démonstration, dont ceux nés dans la péninsule italienne. Boccace écrit ainsi qu'il n'y a pas d'offrande plus agréable à Dieu que «le sang d'un tyran », tandis que Luca de Penna affirme : «Tuer le tyran n'est pas seulement licite, mais équitable et juste». Elle évoque ensuite les positions sur le tyrannicide au moment des guerres de religion, en partie récemment revisitées à l'occasion de la nouvelle question d'histoire moderne proposée au Capes et à l'Agrégation, puis elle aborde successivement plusieurs actes tyrannicides majeurs de la période moderne. Le lecteur pourra ainsi découvrir ou redécouvrir Jacques Clément et Henri III, Ravaillac et Henri IV, ou bien sûr Charles I ${ }^{\mathrm{er}}$ roi déchu et décapité par ses cidevant sujets. D'autres exemples moins connus sont ici mis en lumière, tel celui du meurtre du prince d'Orange, Guillaume de Nassau dit le Taciturne, « le prince hérétique qui a eu l'audace de défier le roi d'Espagne ». Balthasar Gérard, heureux d'avoir accompli son geste meurtrier (1584), est assurément moins connu que Jacques Clément ou Ravaillac, voire Damiens, pourtant sa mise à mort est tout aussi affreuse que la leur : « avoir premièrement la main brûlée en un fer ardent, et puis bras, jambes et endroits charnus de son corps tenaillés avec un fer à diverses fois et en divers endroits la chair brûlée et tenaillée, et le corps tout vif mis en quatre quartiers en commençant par lui ouvrir le ventre et arracher le cœur, et les quatre quartiers mis sur quatre boulevards et la tête sur un pal sur la tour appelée tour de l'école derrière la maison du prince ».

2 Si l'acte de Ravaillac "marque l'apogée du tyrannicide et son reflux ", l'assassin régicide devenant le «monstre» absolu tandis qu'«Henri IV mort devient intouchable ", l'Angleterre vient très vite offrir un nouvel exemple spectaculaire de tyrannicide avec la mise à mort de Charles $\mathrm{I}^{\mathrm{er}}$. Il va de soi que le cas est pour le moins différent, mais certains passages du livre de Monique Cottret ne manquent pas de faire songer à ce que dira Saint-Just au siècle suivant. En effet, au printemps 1649, après l'exécution du roi déchu et alors que la monarchie est supprimée, la loi affirme que la " fonction de roi [...] constitue une charge et un danger pour la liberté, la sécurité et l'intérêt du peuple [...] que toute personne qui détient un tel pouvoir tend naturellement [souligné par moi] à l'utiliser pour empiéter sur la juste liberté du peuple et pour placer sa propre volonté au-dessus des lois [...] ». Quant au sort réservé aux régicides lors de la restauration, nul doute qu'ils ont pu hanter les anciens Conventionnels en 1814-1815. Si Charles II prône une certaine réconciliation nationale et entretient le mythe d'un règne personnel ouvert en 1649, des pamphlets préparent l'opinion et dressent la liste des régicides à punir pour "haute trahison». Le régicide une fois défini comme un parricide, « le simple fait de penser la mort du roi rend coupable ». Chacun connait le sort du cadavre de Cromwell, déterré, pendu au gibet puis décapité; mais on oublie souvent le sort que connurent les vivants, notamment de ceux qui, réfugiés dans des pays étrangers, y furent tués ou enlevés pour être ramenés en Angleterre et jugés. Neuf régicides en 1660, puis trois autres en 1662, sont pendus "sans que mort s'ensuive ", puis éviscérés et enfin écartelés... les bourreaux ayant pour ordre de les conserver le plus longtemps possible en vie afin de ne pas gâcher le spectacle des abominables souffrances infligées aux « coupables ». L'horreur du supplice de Damiens en 1757 n'est hélas guère originale.

3 S'agissant de la Révolution française, à laquelle est attribué le dernier chapitre du livre, Monique Cottret n'apporte pas de véritables nouveautés, mais sa brève synthèse a le mérite de la clarté et surtout d'être fort bien amenée par les treize chapitres 
précédents. Ainsi peut-on mieux comprendre cette "génération des Brutus » et son "tyrannicide dans la transparence». Dans sa conclusion, en écho au beau livre de Sergio Luzzatto, Monique Cottret fait une place aux Conventionnels régicides en 1814-1815 et au-delà, relatant entre autres la longue traque de Le Carpentier de la Manche, exilé en 1816, mais rentré en France au bout d'un mois et caché par des habitants du Cotentin avant d'être capturé et incarcéré au Mont Saint-Michel en 1820. Jean-Louis Ménard, qui lui a consacré un ouvrage en 2001 (Jean-Baptiste Lecarpentier, représentant du peuple délégué par la Convention nationale dans le département de la Manche et autres environnants), avait noté ce commentaire inséré dans le registre des décès du Mont Saint-Michel, au début de l'année 1829: "Comme il n'a pu donner avant de mourir aucun signe de repentir, il est mort sans sacrements; il a été enterré civilement. On a cru devoir, avant de livrer aux vers l'hideuse dépouille de ce monstre, lui couper la tête pour l'étudier d'après le système de Gall ». Lointaine évocation du "monstre » Ravaillac, Le Carpentier et à travers lui tous les Conventionnels ayant voté la mort de Louis devaient être voués à une exécration éternelle des « bons » Français.

4 Assorti d'un index et d'une bibliographie qui rendront bien des services, ce nouveau livre de Monique Cottret vient s'ajouter à tous ceux, nombreux, qu'elle a publiés depuis La Bastille à prendre en 1986. Il passionnera à coup sûr tous ceux et celles qui entendent comprendre comment un "tyran » peut subir un châtiment conçu comme juste et nécessaire, sans pour autant devenir à leur tour des «monstres » pour le seul crime d'avoir... « pensé » la mort d'un roi. 